\title{
1. Collaborative government: meanings, dimensions, drivers and outcomes
}

\section{John Wanna}

Collaboration means joint working or working in conjunction with others. It implies actors-individuals, groups or organisations-cooperating in some endeavour. The participants are 'co-labouring' with others on terms and conditions that, as we know, can vary enormously. The word 'collaboration' originally came into use in the nineteenth century as industrialisation developed, more complex organisations emerged and the division of labour and tasks increased. It was a fundamental norm of utilitarianism, social liberalism, collectivism, mutual aid and, later, scientific management and human relations organisational theory. ${ }^{l}$ Explanations of collaboration could stress the descriptive/pragmatic side focusing on the practical realities of working with or through others, or the normative/intrinsic side emphasising participatory endeavour and the development of trust relations. For the most part, collaboration was portrayed at least as an essential imperative or more ideally as a highly desirable aspect of social, economic and political life.

\section{Meanings and dimensions of collaboration}

Collaboration usually attracts a positive 'spin'. It is often seen as a positive - to collaborate is better, it is creative, transformational and involves beneficial outcomes. There are, however, other dimensions to be considered. Collaborative endeavours can involve the achievement of some outcome or result or, alternatively, the negation or prevention of something happening. We can collaborate for 'good' ends and for 'bad' ends. The context in which collaboration exists is therefore important. The reasons for collaboration occurring are important - as are the means and practices involved, the motivations of the actors, the intended outcomes and the ends involved. To paraphrase Wildavsky, writing in 1973, collaboration and coordination involve several distinct dimensions. First, collaboration could involve cooperation to build commonality, improve consistency and align activities between actors. Second, collaboration can be the process of negotiation, involving a preparedness to compromise and make trade-offs. Third, collaboration can involve oversight roles, checking, pulling together and central coordination. Fourth, collaboration can involve power and coercion, the ability to force outcomes or impose one's own preferences on another, to some extent, with their compliance or involvement. Fifth, collaboration can involve future commitments and intentions, prospective 
behaviour, planning or preparation to align activities. Finally, collaboration can involve engagement, the development of internal motivations and personal commitment to projects, decisions, organisational goals or strategic objectives. It is apparent, even with a cursory glance, that these six dimensions are not necessarily either consistent or complementary with one another-indeed, some could be mutually exclusive.

Collaboration, therefore, is a complex phenomenon. Different aspects of collaborative relations can be evident or come into play in various examples of real collaboration. Different parties could also perceive the collaborative process with diametrically opposed views.

Conceptually, therefore, we have two distinct dimensions of collaboration that intersect continually and differentially: first, the scale or degree of collaboration, and second, the context, purpose or motivation behind collaborative activity. The scale or degree of collaboration categorises patterns of activity that are either evident or intended. It focuses on what levels of collaborative activity are apparent and how extensive are the dimensions of collaboration. In tabular form, the scale of collaboration can be depicted as an escalating ladder of commitment - from the lowest level of perfunctory collaboration to the highest and most elaborate level of integration (this would be similar to Arnstein's ladder of consultation). Table 1.1 lists the levels of collaboration relevant to the policy process and indicates what activities are involved at each of the various levels.

Second, collaboration does not occur in a vacuum. We also need to consider the context, purposes, choices and motivations of actors seeking to collaborate. Here, rather than an escalating ladder, we have a set of possible intentions and motivations that provides us with a range of alternatives or contrasting approaches. These options are listed in Table 1.2.

\section{Table 1.1 The scale of collaboration}

\begin{tabular}{|l|l|}
\hline Degree of collaboration & What is involved-activities \\
\hline $\begin{array}{l}\text { Highest level: high normative } \\
\text { commitment to collaboration; often } \\
\text { highest political/managerial risks }\end{array}$ & $\begin{array}{l}\text { Transformative interaction between network actors; substantive } \\
\text { engagement and empowerment; search for high degree of stakeholder } \\
\text { and inter-actor consensus and cooperation; coalition building by } \\
\text { government and non-government actors }\end{array}$ \\
\hline $\begin{array}{l}\text { Medium-high level: strong normative } \\
\text { orientation; high level of } \\
\text { political/managerial risk }\end{array}$ & $\begin{array}{l}\text { Strong engagement of stakeholders in decisions or policy process } \\
\text { and implementation; devolving decision-making capacities to clients; } \\
\text { more complex innovations in policy-delivery processes }\end{array}$ \\
\hline $\begin{array}{l}\text { Medium level: commitment to multiparty } \\
\text { input and buy-in; moderate levels of } \\
\text { political/managerial risk }\end{array}$ & $\begin{array}{l}\text { Formal commitment to inter-agency consultation and collaboration; } \\
\text { joined government strategies; formal joint involvement exercises and } \\
\text { joint funding initiatives }\end{array}$ \\
\hline $\begin{array}{l}\text { Medium-low level: operational forms } \\
\text { of collaboration to 'get job done'; some } \\
\text { political/managerial risk }\end{array}$ & $\begin{array}{l}\text { Forms of co-production; technical improvements in delivery chains; } \\
\text { assistance to comply with obligations; direct consultation with clients } \\
\text { over delivery and compliance systems; systematic use of evaluation } \\
\text { data; public reporting on targets informed by client preferences }\end{array}$ \\
\hline $\begin{array}{l}\text { Lowest level: marginal operational } \\
\text { adjustments, low levels of } \\
\text { political/managerial risk }\end{array}$ & $\begin{array}{l}\text { Incremental adjustments using consultative processes; client } \\
\text { discussions and feedback mechanisms; gaining information on } \\
\text { needs/expectations of others }\end{array}$ \\
\hline
\end{tabular}


Table 1.2 Contrasting context, purpose, choices and motivations of collaboration

\begin{tabular}{|l|l|l|}
\hline Context \& purpose & Choices or motivational possibilities & \\
\hline Power dimension & Coercive and forced collaboration & $\begin{array}{l}\text { Persuasive and voluntary involvement in } \\
\text { collaboration }\end{array}$ \\
\hline Commitment level & Meaningful and substantive collaboration & Meaningless and cosmetic collaboration \\
\hline Cultural internalisation & $\begin{array}{l}\text { Philosophical commitment to } \\
\text { collaboration-development of } \\
\text { collaborative cultures }\end{array}$ & $\begin{array}{l}\text { Collaboration as a tool, an available } \\
\text { instrument - no real commitment to } \\
\text { collaboration as a modus operandi }\end{array}$ \\
\hline Strategic dimension & $\begin{array}{l}\text { Collaboration for positive and beneficial } \\
\text { reasons }\end{array}$ & $\begin{array}{l}\text { Collaboration for negative and/or } \\
\text { preventive strategies }\end{array}$ \\
\hline Means-ends dimension & $\begin{array}{l}\text { Collaboration as a means and process; } \\
\text { stages, due process }\end{array}$ & $\begin{array}{l}\text { Collaboration as an end and outcome; } \\
\text { shared results, outcome orientation }\end{array}$ \\
\hline Goal dimension & $\begin{array}{l}\text { Shared objectives; mutual intentions, } \\
\text { consensual strategies and outcomes }\end{array}$ & $\begin{array}{l}\text { Competing objectives; different reasons } \\
\text { for participating in collaboration }\end{array}$ \\
\hline $\begin{array}{l}\text { Visibility and awareness } \\
\text { dimension }\end{array}$ & $\begin{array}{l}\text { Overt and public forms of collaboration; } \\
\text { awareness of collaboration is high }\end{array}$ & $\begin{array}{l}\text { Covert and behind-the-scenes } \\
\text { collaboration; unawareness of } \\
\text { collaboration }\end{array}$ \\
\hline Problem applicability & $\begin{array}{l}\text { Collaboration on simple problems; simple } \\
\text { objectives and responsibilities }\end{array}$ & $\begin{array}{l}\text { Collaboration on 'wicked' problems; } \\
\text { defying description and solutions }\end{array}$ \\
\hline
\end{tabular}

\section{Changing patterns of collaboration in public policy: historical eras}

In public policy, we can identify different historical eras with distinct patterns of collaboration, perhaps indicating an evolution of practice. For example, from the outset of Australia as a nation, there was very little attempt to build collaboration into the design of Australian federalism and/or to practise it in the early years of Federation. Indeed, federalism can be interpreted from a Jeffersonian standpoint as an intentionally fragmented model of government with a high degree of decentralised autonomous powers. Jurisdictions retained separate responsibilities (sometimes misleadingly called 'coordinated federalism'). From this perspective, collaboration was not the essence of the chosen system of government, nor was it a particular priority of early governments. Attempts at collaboration would therefore have to work against the structural logic of federalism to succeed, and there would always remain a structural tension in such endeavours. This was characteristic of Australian governments in the first decades after Federation.

Postwar governments believing in Keynesian planning and demand management developed an interest in limited forms of collaboration. Infrastructure projects such as the Snowy Mountains Hydro-Electric Scheme involved multiple governments, inter-jurisdictional cooperation and shared commitments. The welfare state required some inter-agency collaboration and information sharing. Integrated forms of urban and regional planning (while often limited in effect) emphasised collaboration between various public and private entities. In such cases, collaboration often meant command and central coordination. The lessons from this period were mixed: joint action was complex and could stymie development; bad experiences with collaboration were notorious; collaborative 
projects had to be controlled and planned; and often governments did not learn from or build on their experiences of collaboration.

In the era of managerialism and rationalisation of the 1980s and 1990s, governments selectively used competition and forms of collaboration with market players to deliver their core business activities (Entwistle and Martin 2005). They separated roles and responsibilities, then coordinated delivery systems through contract management, funding arrangements and purchaser-provider relations. Governments believed they could improve delivery methods only by engaging in collaboration - which itself implied that they had also to specify outputs or results, control prices and select and monitor external providers. Collaboration occurred less across government than between government and third-party providers - involving individual government agencies and a myriad non-government providers (firms, charity-based and community providers). From the government's perspective, collaboration could involve a range of relationships, from arm's-length, hands-off contract management to close interaction and mutual partnerships. The rationale for greater collaboration was often given in terms of cost containment and economic criteria and/or providing client groups with greater accessibility to government programs. The lessons from this era tended to stress the value of market testing and provision while avoiding incurring new dependencies or capture. Collaboration was often on the government's terms or not at all.

By the turn of the century, governments were becoming interested in higher levels of collaboration - especially in vertical and horizontal collaboration, in whole-of-government integration, joint solutions and in various active partnerships. Governments began to redefine themselves as 'facilitators' engaged in 'value chains' and working through markets, rather than autarkic 'doers' who owned, operated and produced things themselves. They realised and accepted that they were reliant on a host of other actors in order to deliver effective outcomes. These other actors were potentially able to deliver better services because they had special knowledge and skills, had market access or specialisation or concentrated their efforts in key parts of the delivery chains. Four types of collaborative relations between actors became apparent:

- collaboration within government, involving different agencies and players

- collaboration between governments, involving agencies from different jurisdictions

- collaboration between governments and external third-party providers of goods and services

- collaboration between governments and individual citizens/clients.

Policymakers began to recognise new dependencies, the role of extensive policy networks in implementation and the need to reach out to other bodies with interests in shared outcomes. Collaboration was now a widely used policy 
instrument across the fields of public policy. Governments relied on collaboration to improve policy formulation (using such bodies as consultants and think tanks). They used collaboration to improve implementation and provide more integrated services (using firms, charity organisations and community associations). Governments could extend access regimes and widen the reach of policy using a matrix of local players, incentive payments and one-stop shops. Collaboration became an essential modus operandi for coping with crisis management and emergency situations, involving the coordination and mutual assistance of diverse specialist agencies. Collaboration now took on the mantle of managing mutual dependencies using diplomacy, dialogue and deliberation. Collaborators on all sides, however, questioned the effort-value equation and searched for ways to predict the ingredients of successful collaboration.

The vocabulary of governments also changed. They began to talk of engagement, connected government and collaboration as a new era of public administration ('public administration of the future'). In part, the language change was strategic and transformational, but in part it was also exhortatory (encouraging administrators to attempt collaboration to assist them in doing their jobs better). Collaboration was not framed within the mind-set of bureaucracy, but was beyond bureaucracy. Collaboration was by now the next wave of public-sector reform (after hierarchy, managerialism, 'new public management' and outsourcing and market delivery). It allowed governments to reconsider where they could best direct their strategies and energies to achieve desired outcomes. Governments sometimes chose to keep selected services or assets in public hands (for example, the benefit-payments system, the national rail track, regimes of safety regulation), but such decisions were made because governments felt they then had the appropriate springboard to build collaborative arrangements to deliver preferred outcomes. Governments began to build networks, coalitions and partnerships, but these arrangements were not meant as ends in themselves; rather, the investment in such collaborative arrangements was intended to improve services and government-to-citizen relations. Collaboration began to mean working with and through others for greater effectiveness.

If we look internationally at which nations are leading the way in the promotion of collaboration as an issue of good governance, we find the discourse is strongest in the Anglo-American nations that have undergone new public management reforms - especially in Westminster systems with strong executive governments. Why do we detect this trend? Reasons could include that the public sector in these nations is 'post-managerialist', there is a reduced role for and belief in hierarchies, governments have attempted to de-silo their administrative organisations and have introduced contractualism and commercial principles in policy implementation and delivery. US and Westminster-style systems have also tended to display less emphasis on ministerial autonomy in departments (compared with continental European or Asian governments), and have stronger 
traditions of coordination through and across cabinet. Central and line agencies in these countries overtly recognised the need for collaboration across government jurisdictions and agencies (and eventually collaboration with business and community organisations).

\section{Drivers of collaboration today}

We can cluster the drivers of collaboration under three headings: external drivers, internal drivers and volition in relation to the roles and responsibilities of government. External drivers include the pressures of globalisation, greater international connectedness and travel, knowledge of other cultures, information technology (IT) and technological sophistication. Economic pressures have also played a crucial role - with the push to develop world markets, global trade, international investment patterns, business aggregations and demand for uniform regulation, competitive neutrality and specialisation. Terrorism and national security concerns (including immigration and people movement) have also crystalised these global pressures in ways that go to the heart of the authoritative nature of the State. Global environmental, physical and resource pressures have forced governments to engage in international dialogue and action to manage these problems. Community demands, education, changing demographics and social structures have also changed expectations and understandings.

Internal drivers and preconditions within government include the political demands for public officials to be 'responsive' to community needs. Policy reach and accessibility are powerful drivers, as are policy orientations towards mutual obligation and reciprocity. Making policy outcomes more effective is also a major factor. This can include responsive resource systems, flexible budgetary frameworks and the managerial focus on outcomes and performance results. The growing preference for and greater reliance on contract provision necessitates basic forms of collaboration with external providers and the management of relations. Capacity issues inside government agencies and the changing composition and skills base of the public sector (from an operational focus to an emphasis on policy and management roles, with staff recruits shifting from school-leavers to graduates) have made collaboration a necessary imperative of modern management.

Volition factors include political strategies for shared goals and understanding of problems across the community-building consensus among players and coalitions of support for particular action. Part of the impetus behind volition is the desire for a new activism in government, to develop new policy agendas, take on wider responsibilities and remake policy frameworks to suit the changing times. Governments have declared their intentions to deliver 'seamless government', wired-up services, joint policy solutions and integrated services. Their public commitment to new performance-reporting regimes underscores these strategies. 


\section{Advantages and opportunities versus disadvantages and weaknesses}

The advantages of collaboration are that it often assists policymakers to identify and target problems and achieve stakeholder agreement or acceptance of directions or decisions. It can be a means to better policy solutions that have greater traction in the community. It can contribute new visions or perspectives on problems and thus offer new opportunities to implement strategies for change. It can allow governments to take the initiative and get on the front foot. For public officials engaged in policy formulation, it can be either a way of genuinely opening up the policy process to wider ideas and suggestions or a way of road-testing ideas and collating responses before implementation. For non-government players, it allows them to understand better the thinking and practices of government and to exert some influence on policy determination or amendment.

Collaboration can lead to mutual learning and shared experience. It can provide direction for capacity building inside and outside organisations (either through the recruitment of different profiles and skills or the development of networks of supportive/dependent contributors). Many government agencies now work jointly with private-sector providers to the mutual benefit of both parties. A commitment to collaboration is also likely to drive organisational change and affect resource reallocation. It can spawn new organisational and interactive forums - from dedicated task forces to reference groups and advisory bodies, or from new authorities and policy forums to new intergovernmental bodies.

Collaboration in implementation has the advantages of clarifying roles and responsibilities, combining relevant skills and capacities, allowing specialisation and enabling public bureaucracies to be far more effective in delivering policy to the ground. It can be used to develop markets and bring into the policy process additional players who were not previously involved. It can also make governments conscious of the real value-for-money issues involved in delivering policy effectively (specifying outputs, prices, reporting requirements, and so on).

The disadvantages or weaknesses that could be experienced with collaborative activities include the difficulties of ensuring political or ministerial buy-in to arrangements of additional complexity. Ministers could show little interest in such initiatives or ask why they should volunteer to extend their political accountabilities, especially when they are likely to have less and less control over the outcomes. Politicians could regard collaboration as a way of losing control, not of gaining greater leverage over policy options. They could also fear that collaboration increases the political risks for them as politicians but not for others in the system. 
Collaboration can blur lines of accountability even further than their current state. This raises questions about who is responsible for what and who is ultimately accountable for decisions taken, if problems emerge or if things go wrong. Collaboration can increase the blame game and excite complaints when the expectations of stakeholders are not met or are frustrated. Indeed, the promise of collaboration can heighten expectations that are likely to be dashed in practice.

Collaboration can frustrate rather than expedite decision making. Interdepartmental committees once had the reputation of being the graveyard of decision making; the combatants of such committees went along to meetings to defend their turf and prevent decisions being taken contrary to their interests. Many considered a successful outcome of such meetings was that no decision was taken or that potential action was averted.

Non-government actors can have other problems. From the viewpoint of business and community associations, they could feel that they are not necessarily bound by collective processes or consensual agreements - or cannot speak for their sector or ensure compliance with collective agreements. Governments can impose formal or informal constraints on their behaviour-imposing 'gag' conditions in legal contracts, insisting on vetting public comments or presentations and vetoing the selection of staff working for non-governmental organisations. Conversely, non-government actors can disengage and disrupt policy delivery at times of their own choosing, and have no real accountability for any final outcome.

Collaborative exercises can run at cross-purposes if the objectives and incentives of the participants are not aligned or compatible. Shared preferences can be the exception rather than the rule. For some technical purists or expert specialists in the policy process, collaboration can be perceived as leading to second-best solutions (or even to lowest common denominator solutions) if participants possess veto rights or can sway decisions (even if such outcomes are workable).

Governments have attracted criticism for not being entirely genuine in collaborative engagements. Collaboration can be undertaken for ulterior political motives. It can be cosmetic or a smokescreen for action. It can be used to 'sell' decisions decided elsewhere or taken previously by departments. Collaboration then becomes an exercise in the dissemination and promotion of government policy. Such examples of perfunctory collaboration can undermine trust in government and in the policy process more generally.

\section{Lessons from collaboration}

One of the main aims of this monograph is to identify and debate the substantive lessons from real experiences of collaboration in the public sector but involving the private sector and the wider community - to enable policymakers to better understand the processes and the range of possibilities available. We aim to 
analyse the 'black box' of opacity that often characterises the practice of collaboration (Thomson and Perry 2006). Already from experiences and from the literature, we know that collaborative arrangements are costly in time and resources, are inherently fragile, need to be constantly managed and nurtured, involve trust and reciprocal obligations and are sui generis or uniquely distinct (Huxham 2005; Entwistle and Martin 2005; Agranoff 2006; Bardach 1998; and, for the private sector, see Simonin 1997). We know that successful collaboration requires commitment, trust, leadership, clarity of objectives and planning stages, developing understanding and mutual working relations (Huxham and Vangen 2000). From within government there is a belief that collaboration works best when responsibilities are clear and when a lead agency or 'champion' has been selected. Is this empirically valid? Can responsibilities be clearly separated in collaborative ventures and can leadership be successfully anointed in an a priori manner? How can the momentum for collaboration be generated and sustained?

In this monograph, many of the contributors speak from years of practical experience engaged in collaborative endeavours. Many identify general lessons from their specific if diverse experiences. Some of the lessons highlight the perspectives of the individual players (the official, the community representative, the business manager, or the end user) about what collaboration entails, how it impacts on them and how players can collaborate better. Others present collaboration as a new organising principle of government and policymaking - a structured set of collective choices from which new policy possibilities develop and germinate - feeding into policy formulation, implementation and evaluation. Others tend to see collaboration as a new form of democratic engagement bringing substantial deliberative benefit to the development of good public policy and quality services. Others disseminate comparative policy learning from overseas - indicating how other jurisdictions have gone about the journey of collaboration in policy setting, encouraging policy transfer or emulation and illustrating how beneficial outcomes have been achieved in their particular context.

We hope that the sharing of this combined learning, experience and understanding will inform governments and policy processes into the future - and give non-government participants and policy networks a realistic if not sanguine view of the potentialities and implications of collaborative government. Governing through collaboration will change not only how we make policy, it will change what policy is made and who cooperates in its delivery. Collaboration poses a major challenge to the traditional ways of making policy and to the conventional departmental cultures of 'government knows best'. Governing though collaboration throws out many challenges to all players in almost all policy fields; it poses challenges but also opens the possibility of truly sustained improvements in the quality of implementation and service delivery. 


\section{References}

Agranoff, R. 2006, 'Inside collaborative networks: ten lessons for public managers', Public Administration Review, December.

Bardach, E. 1998, Getting Agencies to Work Together: The practice and theory of managerial craftsmanship, Brookings Institution, Washington, DC.

Entwistle, T. and Martin, S. 2005, 'From competition to collaboration in public service delivery: a new agenda for research', Public Administration, vol. 83, no. 1 .

Huxham, C. 2005, Managing to Collaborate: The theory and practice of collaborative advantage, Routledge, New York.

Huxham, C. and Vangen, S. 2000, 'Leadership in the shaping and implementation of collaboration agendas', Academy of Management Journal, vol. 43, no. 6.

Simonin, B. 1997, 'The importance of collaborative know-how: an empirical test of the learning organisation', Academy of Management Journal, vol. 40, no. 5 .

Thomson, A. M and Perry, J. L. 2006, 'Collaboration processes: inside the black box', Public Administration Review, December.

Watt, I. and Dangerfield, G. 2007, Arrangements for Facilitating Trans-Tasman Government Institutional Co-operation, Australia New Zealand School of Government, Carlton, Victoria.

Wildavsky, A. 1973, 'If planning is everything, maybe it's nothing', Policy Sciences, Volume 4, no.2, pp. 127-153.

\section{ENDNOTES}

1 Thomson and Perry (2006:20) state that collaboration in the United States has its roots in two competing political traditions: classic liberalism (market individualism requiring preferences and exchange) and civic republicanism (community integration of shared preferences). 